\title{
Cancer neovasculature-targeted near-infrared photoimmunotherapy (NIR-PIT) for gastric cancer: different mechanisms of phototoxicity compared to cell membrane-targeted NIR-PIT
}

\author{
Takashi Nishimura $^{1} \cdot$ Makoto Mitsunaga $^{1}\left[\right.$ [ ${\text { Kimihiro } \text { Ito }^{1} \cdot \text { Hisataka Kobayashi }}^{2} \cdot$ Masayuki Saruta $^{1}$
}

Received: 5 April 2019 / Accepted: 4 July 2019 / Published online: 13 July 2019

(c) The International Gastric Cancer Association and The Japanese Gastric Cancer Association 2019

\begin{abstract}
Background Near-infrared photoimmunotherapy (NIR-PIT) constitutes a new class of molecular-targeted theranostics utilizing monoclonal antibody (mAb)-photosensitizer conjugates and NIR light. In this study, we developed a new type of NIR-PIT targeting vascular endothelial growth factor receptor 2 (VEGFR-2) expressed on vascular endothelium in an experimental gastric cancer model and evaluated the feasibility by comparing conventional NIR-PIT targeting cancer cell membrane in vitro and in vivo.

Methods HER2-positive human gastric cancer cells, NCI-N87, were used for the experiments. Anti-HER2 mAb, trastuzumab and anti-VEGFR-2 mAb, DC101 were conjugated to photosensitizer, IR700. Phototoxicity in response to NIR-PIT were investigated in vitro and in vivo. Microvessel densities, as an indicator of angiogenesis, were counted in harvested xenografts after NIR-PIT to elucidate the mechanism.

Results DC101-IR700 did not induce phototoxic effect in vitro because of the absence of expression of VEGFR-2 in NCIN87 cancer cells. However, it induced an antitumor effect in NCI-N87 xenograft tumors accompanied with damage in tumor neovasculature as determined by decreasing tumor microvessel density, which represents a different mechanism than that of conventional NIR-PIT targeting antigens expressed on the tumor cell membrane.

Conclusion We demonstrated a new approach of NIR-PIT utilizing a target on vascular endothelium, such as VEGFR-2, and this treatment might lead to the development of a new therapeutic strategy for human gastric cancer.
\end{abstract}

Keywords Near-infrared photoimmunotherapy $\cdot$ Monoclonal antibody $\cdot$ Photosensitizer $\cdot$ VEGFR- $2 \cdot$ Cancer neovasculature

\begin{tabular}{|c|c|}
\hline \multicolumn{2}{|c|}{ Abbreviations } \\
\hline APC & $\begin{array}{l}\text { Monoclonal antibody photosensitizer } \\
\text { conjugate }\end{array}$ \\
\hline ICD & Immunogenic cell death \\
\hline DAPI & 4',6'-Diamidino-2-phenylindole \\
\hline
\end{tabular}

Electronic supplementary material The online version of this article (https://doi.org/10.1007/s10120-019-00988-y) contains supplementary material, which is available to authorized users.

Makoto Mitsunaga

mit@jikei.ac.jp

1 Division of Gastroenterology and Hepatology, Department of Internal Medicine, The Jikei University School of Medicine , 3-25-8 Nishishinbashi, Minato, Tokyo 105-8461, Japan

2 Molecular Imaging Program, Center for Cancer Research, National Cancer Institute, NIH, Building 10, Room B3B69, 10 Center Drive, Bethesda, MD 20892-1088, USA
HER2 Human epidermal growth factor receptor 2 IR700 IRDye700DX $N$-hydroxysuccinimide ester $\mathrm{mAb} \quad$ Monoclonal antibodies

MVD Microvessel density

MFI Mean fluorescence intensity

NIR-PIT Near-infrared photoimmunotherapy

VEGFR-2 Vascular endothelial growth factor receptor 2

\section{Introduction}

Mainstays of cancer treatment include surgery, radiation therapy, and chemotherapy. Additionally, many moleculartargeted agents, such as monoclonal antibodies $(\mathrm{mAb})$ and tyrosine kinase inhibitors, lead to improved survival outcomes of patients with cancer. However, efficacy of mAb as a monotherapy is generally limited; therefore, antibody-drug 
conjugates have been recently developed to enhance therapeutic efficacy.

Trastuzumab constitutes a recombinant humanized IgG1 $\mathrm{mAb}$ that specifically binds to human epidermal growth factor receptor 2 (HER2) expressing at the cell membrane, leading to inhibited cell proliferation, adhesion, migration, and differentiation [1]. Up to $34 \%$ of patients with gastric cancer show HER2 amplification or overexpression [2-4], and the ToGA trial showed that trastuzumab supplementation to chemotherapy significantly improved overall survival compared with chemotherapy alone in patients with high HER2 protein expression [5]. In turn, DC101 represents a rat IgG1 mAb targeting the extracellular domain of mouse vascular endothelial growth factor receptor 2 (VEGFR-2) expressed on tumor vasculature. DC101 has been made to provide as a surrogate $\mathrm{mAb}$ for ramucirumab that is a fully humanized IgG1 mAb against human VEGFR-2 [6], since ramucirumab is not cross-reactive with mouse VEGFR-2, and its antitumor activity and anti-angiogenic mechanism of action could not be studied in the mouse. Angiogenesis is regulated principally by interactions between VEGFs and VEGFRs, and plays a key role in cancer growth and metastasis [7-11]. In animal models of human gastric adenocarcinoma, VEGFR-2 inhibition by DC101 led to reduced tumor growth and vascularity [12]. Moreover, REGARD and RAINBOW trials showed that ramucirumab monotherapy or in combination with chemotherapy significantly improved overall survival compared with placebo or placebo plus chemotherapy in patients with metastatic or unresectable gastric cancer [13, 14].

Near-infrared photoimmunotherapy (NIR-PIT) is a new class of cancer therapy based on a mAb conjugated to a photosensitizing phthalocyanine dye, IR700 (IRDye700DX), followed by NIR light irradiation under the guidance of molecular-targeted fluorescence imaging [15]. Upon tumor cell exposure to NIR light, the mAb-IR700 conjugate leads to rapid and target-selective cell death consequent to necrosis. A recent clinical trial on epidermal growth factor receptor (EGFR)-targeted PIT in patients with unresectable head and neck cancer has shown promise in a Phase $1 / 2$ clinical trial (NCT02422979). Previous studies demonstrated the antitumor effect of NIR-PIT using trastuzumab conjugated to IR700 (Tra-IR700) for HER2-positive cancer cell lines [16-22]. However, some cancer cells survive and regrow after NIR-PIT in an in vivo model partly because of heterogeneous mAb-IR700 conjugate distribution in the tumor [3, $23,24]$. Additionally, various mAb-IR700 conjugate types are required to treat tumors exhibiting heterogeneity because NIR-PIT antitumor effect is dependent on target antigen expression level. To address these drawbacks, we hypothesized that NIR-PIT using DC101-IR700 conjugate (DC101IR700) targeting VEGFR-2 expressed on vascular endothelium would exert antitumor effects. Whereas conventional
NIR-PIT targets specific molecules on the tumor cell membrane, NIR-PIT utilizing DC101-IR700 selectively damages the tumor vascular endothelium, affording antitumor effects by angiogenesis inhibition, a different mechanism of phototoxicity than by conventional NIR-PIT. The aim of this study was to evaluate the efficacy of tumor vasculature-targeted NIR-PIT using DC101-IR700 and compare the mechanism of antitumor effect with that of conventional NIR-PIT.

\section{Materials and methods}

\section{Reagents}

Trastuzumab was purchased from Chugai Pharmaceutical Co., Ltd. (Tokyo, Japan), and DC101 was purchased from BioXcell (West Lebanon, NH, USA). IRDye700DX $\mathrm{N}$-hydroxysuccinimide ester (IR700) was obtained from LICOR Biosciences (Lincoln, NE, USA), Alexa Fluor488 NHS ester (Alexa488) from Life Technologies (Gaithersburg, MD, USA), and Cyanine5 NHS ester (Cy5) from Lumiprobe (Hallandale Beach, FL, USA).

\section{Synthesis of IR700, Alexa488 or Cy5-conjugated antibodies}

Trastuzumab (1.0 mg, $6.8 \mathrm{nmol})$ and DC101 $(1.0 \mathrm{mg}$, $6.6 \mathrm{nmol})$ were incubated with IR700 (66.8 $\mu \mathrm{g}, 34.2 \mathrm{nmol})$ in $0.1 \mathrm{M} \mathrm{Na}_{2} \mathrm{HPO}_{4}(\mathrm{pH} \mathrm{8.5)}$ at room temperature for $1 \mathrm{~h}$. The mixture was purified with a Sephadex G50 column (PD10; GE Healthcare, Piscataway, NJ, USA). Likewise, trastuzumab was incubated with Cy5 $(62.9 \mu \mathrm{g}, 102.0 \mathrm{nmol})$ and DC101 was incubated with Alexa488 (65.6 $\mu \mathrm{g}, 102.0 \mathrm{nmol})$ and purified as above. Protein, IR700, Alexa488, and Cy5 concentrations were determined spectrophotometrically by measuring absorption at 280, 494, 649, and $689 \mathrm{~nm}$ (UV1800; Shimadzu Corp., Kyoto, Japan) to confirm the number of fluorophore molecules conjugated to each antibody molecule. This number was adjusted to approximately 3 for IR700 and 2 for Alexa488 and Cy5.

\section{Cell culture}

HER2-expressing human gastric cancer cell line NCI-N87 was purchased from American Type Culture Collection (ATCC) (Manassas, VA, USA), as was HER2-negative BALB/3T3 cells as negative controls. HER2-negative human gastric cancer cell line, MKN45 cells were purchased from RIKEN Cell Bank (Tsukuba, Japan). Cells were cultured with RPMI 1640 (Life Technologies) supplemented with $10 \%$ fetal bovine serum and $1 \%$ penicillin/streptomycin (Life Technologies) in tissue culture flasks in a humidified incubator at $37^{\circ} \mathrm{C}$ in an atmosphere of $95 \%$ air and $5 \% \mathrm{CO}_{2}$. 


\section{Fluorescence microscopy}

Fluorescence microscopy was performed using an IX73 fluorescence microscope (Olympus, Tokyo, Japan) to confirm molecular target-specific localization of mAb-IR700 in NCI-N87 cells. Cells were seeded on cover glass-bottomed dishes and incubated for 24 to $48 \mathrm{~h}$ at $37{ }^{\circ} \mathrm{C}$. Tra-IR700 $(10 \mu \mathrm{g} / \mathrm{ml})$ or DC101-IR700 $(10 \mu \mathrm{g} / \mathrm{ml})$ was added to the culture medium and incubated for $3 \mathrm{~h}$ at $37^{\circ} \mathrm{C}$. Then, cells were washed with phosphate-buffered saline (PBS) and fluorescence microscopy was performed with the filter settings: 608-648 nm excitation and 672-712 $\mathrm{nm}$ emission for IR700. Fluorescence images were analyzed with ImageJ software (https://rsb.info.nih.gov/ij/).

\section{Flow cytometry}

To analyze expression levels of HER2 and VEGFR-2 in NCI-N87 cells, IR700 fluorescence was measured by flow cytometry (MACSQuant analyzer; Miltenyi Biotec, Bergisch Gladbach, Germany). Cells were seeded in 35-mm dishes and cultured for $48 \mathrm{~h}$. After $3 \mathrm{~h}$ incubation with $10 \mu \mathrm{g} / \mathrm{ml}$ Tra-IR700 or DC101-IR700, the media were removed, plates washed with PBS, and flow cytometric analysis performed. The mean fluorescence intensities (MFIs) were calculated and compared to the isotype control. Additionally, to confirm target specificity, unconjugated trastuzumab $(100 \mu \mathrm{g} /$ $\mathrm{ml})$ or DC101 $(100 \mu \mathrm{g} / \mathrm{ml})$ were added to the cells to block the HER2 or VEGFR-2 molecules prior to incubation with the Tra-IR700 or DC101-IR700 conjugate.

\section{In vitro NIR-PIT and cytotoxicity assay}

Cells were seeded on cell culture dishes and incubated for $48 \mathrm{~h}$ at $37^{\circ} \mathrm{C}$. The medium was replaced with fresh phenol red-free RPMI 1640 containing Tra-IR700 $(10 \mu \mathrm{g} / \mathrm{ml})$ or DC101-IR700 $(10 \mu \mathrm{g} / \mathrm{ml})$. Cells were incubated for another $24 \mathrm{~h}$ at $37^{\circ} \mathrm{C}$, washed with PBS, and fresh phenol red-free RPMI 1640 added. Cells were irradiated with NIR light using a $690 \mathrm{~nm}$ continuous wave laser (ML6540-690; Modulight, Inc., Tampere, Finland). Power density of $29.5 \mathrm{~mW} /$ $\mathrm{cm}^{2}$ was measured with an optical power meter (PM100, Thorlabs, Newton, NJ, USA). Irradiation doses for each dish were 0,1 , and $3 \mathrm{~J} / \mathrm{cm}^{2}$, respectively. After irradiation, cells were collected and resuspended with PBS, followed by LIVE/DEAD cytotoxicity assay (Life Technologies), which can detect damaged cellular membranes as a shortterm cytotoxicity assay. Viable cells were counted over time using an automated cell counter (Countess; Life Technologies) based on trypan blue dye uptake as a long-term cytotoxicity assay.

\section{Xenograft tumor model}

All animal studies were conducted in accordance with the guidelines established by the Animal Care Committee of the Jikei University School of Medicine. We obtained 6-weekold female BALB/c-nu mice (CAnN.Cg-Foxn $1^{n u} / \mathrm{Crl}-\mathrm{Crlj}$ ) from Charles River Laboratories Japan, Inc. (Yokohama, Japan). All mice were allowed to acclimatize for 1 week before the studies, and were maintained under a controlled light-dark cycle $(12: 12 \mathrm{~h})$. We injected $5 \times 10^{6} \mathrm{NCI}-\mathrm{N} 87$ cells subcutaneously into the mouse right dorsum, with $5 \times 10^{6}$ BALB $/ 3$ T 3 cells injected subcutaneously into the left dorsum as a control. Tumor xenografts were measured using an external caliper and tumor volume was calculated using the following formula: length $\times$ width $\times$ height $\times 0.5$ [25].

\section{In vivo fluorescence imaging}

To determine Tra-IR700 and DC101-IR700 biodistribution, fluorescence images were obtained with the IVIS ${ }^{\circledR}$ Imaging System (Caliper Life Sciences, Hopkinton, MA, USA) using 675-nm excitation and 695-770-nm emission filters. Xenograft tumors reached approximately $100 \mathrm{~mm}^{3}, 14$ days after NCI-N87 cell injection. Tra-IR700 or DC101-IR700 $(100 \mu \mathrm{g})$ were injected intravenously. Fluorescence images were obtained serially starting 1 day after mAb-IR700 injection under the same setting (e.g., exposure time, camera binning, and stage height), and target tumor fluorescence intensities were analyzed. All fluorescence images were analyzed using Living Image ${ }^{\circledR}$ Software. The region of interest was manually determined for each tumor area depending on IR700 fluorescence localization site.

\section{Microdistribution analysis of fluorescence probe-labeled antibody in $\mathrm{NCI}-\mathrm{N} 87$ tumor xenografts}

To investigate the tumor microdistribution of trastuzumab and DC101 in harvested NCI-N87 tumors, $100 \mu \mathrm{g}$ Tra-Cy5 and DC101-Alexa488 were injected intravenously into NCIN87 tumor-bearing mice. NCI-N87 tumors were harvested and fixed overnight in $4 \%$ paraformaldehyde dissolved in $0.01 \mathrm{M}$ PBS, immersed in graded concentrations of sucrose in PBS (10\% for $1 \mathrm{~h}, 20 \%$ for $1 \mathrm{~h}$ ), embedded in OCT compound, and stored at $-80{ }^{\circ} \mathrm{C}$. Microscopic fluorescence imaging of frozen tissue sample sections were acquired as $10-\mu \mathrm{m}$ slice sections on glass slides with nuclear counter staining by 4',6'-diamidino-2-phenylindole (DAPI). Confocal imaging was performed with a ZEISS LSM 880 (Carl Zeiss, Jena. Germany). To detect DAPI, Alexa488, and Cy5 fluorescence, 405, 488, and $633 \mathrm{~nm}$ lasers were used for excitation, and emitted fluorescence was acquired with band pass filter settings of 410-498, 498-598, and 637-755 nm, 
a

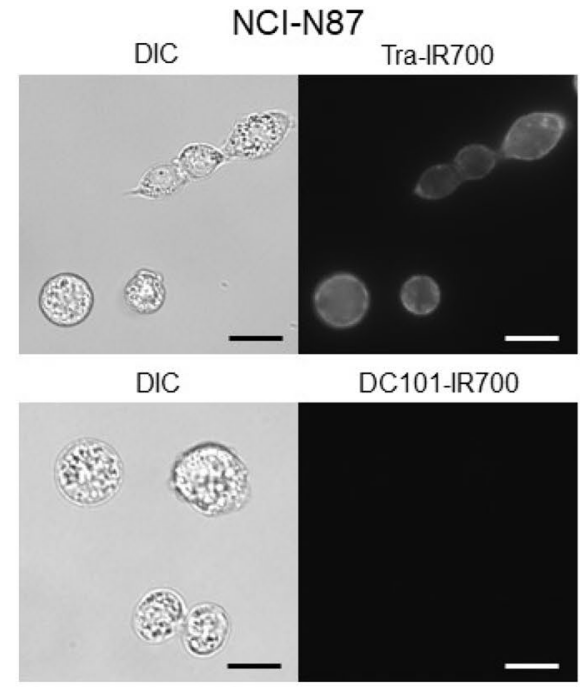

C

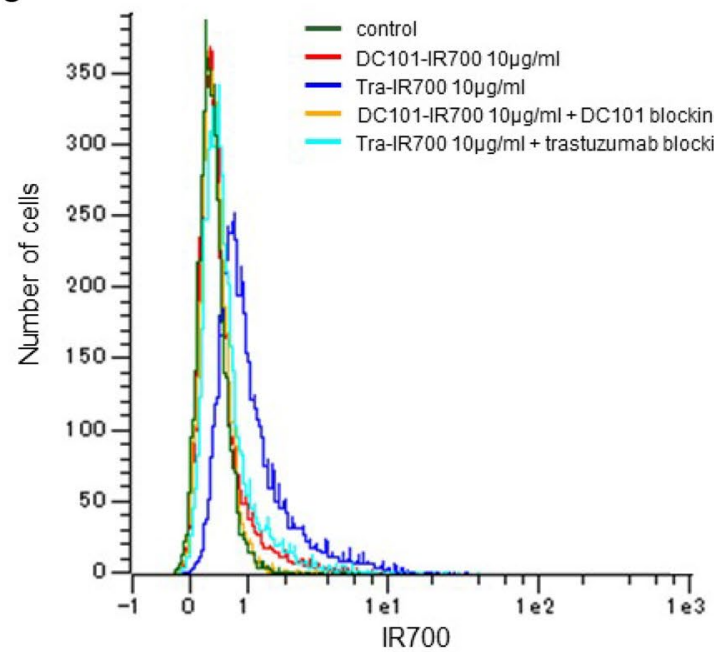

b
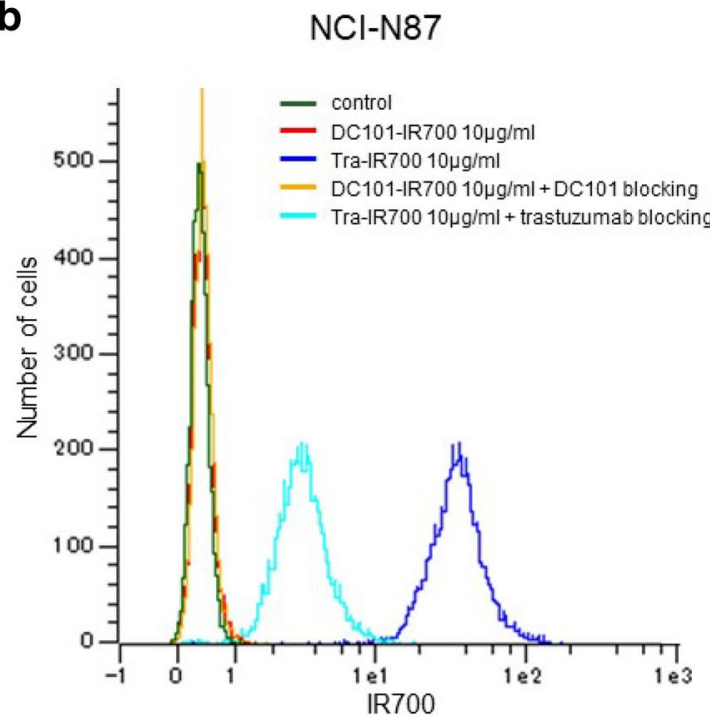

d

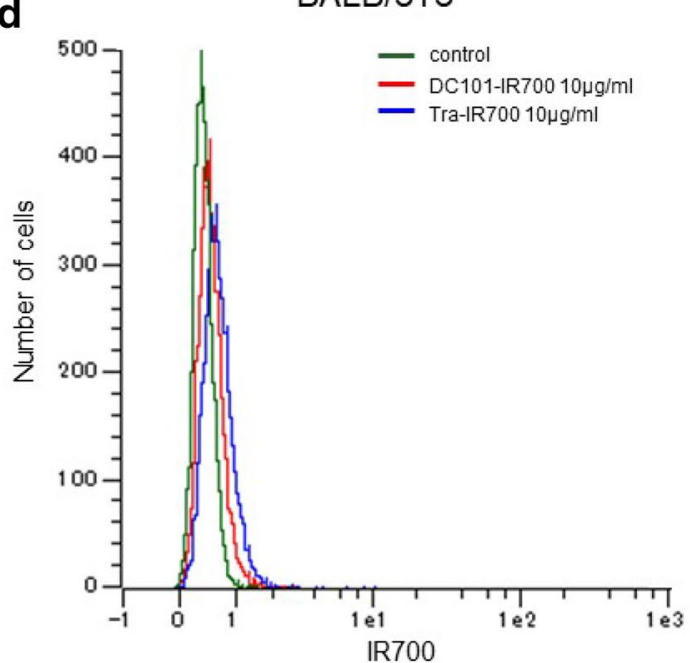

e

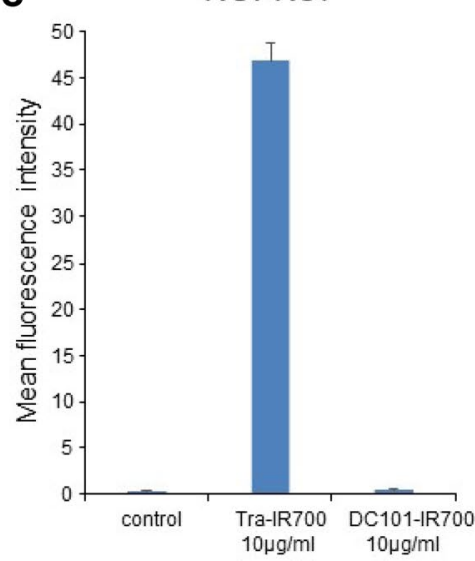

MKN45

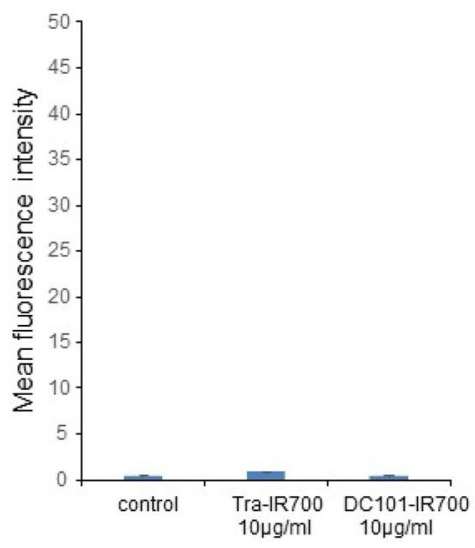

BALB/3T3

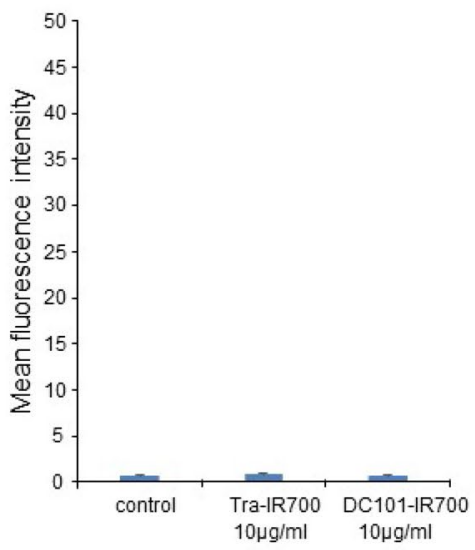

respectively. Further, sections removed after administration of Tra-Cy 5 were incubated with $5 \mathrm{mg} / \mathrm{ml}$ of Tra-Alexa 488 for $2 \mathrm{~h}$ at $25^{\circ} \mathrm{C}$; the cells were washed and analyzed by confocal microscope to clarify whether there is a difference between the distribution of administered Tra-Cy5 and stained Tra-Alexa488. 
4Fig. 1 VEGFR-2 and HER2 expression in NCI-N87 cells in vitro. a Fluorescence microscopy showing HER2-specific localization of Tra-IR700 in NCI-N87 cells, whereas fluorescence of DC101-IR700 was not detected. Scale bar $20 \mu \mathrm{m}$. DIC differential interference contrast. b Flow cytometry analysis reveals strong specific binding of Tra-IR700 in NCI-N87 cells but not of DC101-IR700. Specific binding of Tra-IR700 is demonstrated by excess unconjugated trastuzumab blocking. c, d Few signals of Tra-IR700 and DC101IR700 are seen in MKN45 and BALB/3T3 cells. e Quantification of mean fluorescence intensity of Tra-IR700 and DC101-IR700 in NCI-N87, MKN45 and BALB/3T3 cells. Data are presented as the means $\pm \operatorname{SEM}(n=3)$

\section{In vivo NIR-PIT}

Mice bearing NCI-N87 tumor xenografts reaching approximately $100 \mathrm{~mm}^{3}$ in volume 14 days after NCIN87 cell injection were selected and randomized into 6 groups ( $n=10$ mice in each group): intravenous injection of PBS without (no treatment) (1) or followed by NIR light irradiation $\left(50 \mathrm{~J} / \mathrm{cm}^{2}\right)(2)$; intravenous injection of $100 \mu \mathrm{g}$ Tra-IR700 (3), or DC101-IR700 (4) without NIR light irradiation; and intravenous injection of $100 \mu \mathrm{g}$ TraIR700 (5), or DC101-IR700 (6) followed by NIR light irradiation $\left(50 \mathrm{~J} / \mathrm{cm}^{2}\right) 1$ day after injection. NIR light irradiation was performed under isoflurane anesthesia with a $690-\mathrm{nm}$ continuous wave laser at a power density of $330 \mathrm{~mW} / \mathrm{cm}^{2}$. After the treatments, tumor volumes were measured 3 times a week until the volume reached $1000 \mathrm{~mm}^{3}$.

\section{Immunohistochemistry}

To examine tumor microvasculature, immunohistochemical staining was performed using anti-mouse CD31 mAb (Dianova, DIA-310, Hamburg, Germany). NCI-N87 tumor-bearing mice were killed $24 \mathrm{~h}$ after NIR-PIT treatment and tumors were harvested, formalin-fixed, and paraffin-embedded. For immunohistochemical staining with anti-CD31 antibody, sections were pretreated with $0.3 \%$ hydrogen peroxide in methanol to block endogenous peroxidase activity, and with $10 \%$ bovine serum albumin, $10 \%$ fetal bovine serum, and $0.02 \% \mathrm{NaN}_{3}$ in PBS to block nonspecific binding sites. Sections were then incubated with primary antibodies against CD31 $(1: 40)$ at $4{ }^{\circ} \mathrm{C}$ overnight, and then incubated with ImmPRESS HRP Anti-Rat IgG (Peroxidase) Polymer Detection Kit (Vector Laboratories, Burlingame, CA, USA), at room temperature for $30 \mathrm{~min}$. Reactions were visualized by incubating sections with ImmPACT DAB Peroxidase Substrate Kit (Vector Laboratories) for $5 \mathrm{~min}$. The sections were stained with hematoxylin for visualization of nuclei, and then mounted on glass slides.

\section{Microvessel density analysis}

Tumor microvessel density (MVD) was determined as described previously $[6,26]$ and assessed by counting the microvessels immunostained with anti-CD31 antibody. The slides were screened under $40 \times$ magnification (low-power field) to identify the highest vascular density area within the tumor. Sclerotic areas where microvessels were sparse were not considered in vessel counts. Vessels were counted in the five areas of highest vascular density at $200 \times$ magnification (high-power field). The mean vessel count in these five areas was expressed as the MVD. Any brown-staining endothelial cell or endothelial cell cluster that was clearly distinguishable from background, and separate from adjacent microvessels, tumor cells, and other connective tissue elements was considered as a single microvessel. Branching structures were counted as a single vessel unless there was a break in structure continuity.

\section{Tumor microdistribution analysis after NIR-PIT}

To investigate the tumor microdistribution of Tra-IR700 conjugates after NIR-PIT treatment, NCI-N87 tumors were treated with either DC101-IR700 or Tra-IR700 followed by NIR light irradiation $\left(50 \mathrm{~J} / \mathrm{cm}^{2}\right)$. Intravenous injection of Tra-IR700 $(100 \mu \mathrm{g})$ was performed just after NIR light irradiation. Tumors were then harvested $24 \mathrm{~h}$ after injection, followed by microscopic fluorescence imaging (Olympus IX73).

\section{Statistical analysis}

Data are expressed as the means \pm SEM from a minimum of three experiments. Statistical analyses were carried out using GraphPad Prism software (GraphPad Software Inc., La Jolla, CA, USA). Student's $t$ test was used to compare the two treatment groups. The cumulative probability of survival was estimated in each treatment group by Kaplan-Meier survival curve analysis, and results were compared by the logrank test. $P<0.05$ was considered to indicate a statistically significant difference.

\section{Results}

\section{VEGFR-2 and HER2 expression in NCI-N87 cells in vitro}

Fluorescence signals of Tra-IR700 or DC101-IR700-treated NCI-N87 cells were examined by fluorescence microscopy and flow cytometry. HER2-expressing NCI-N87 cells showed strong lysosomal and membrane Tra-IR700 localization, whereas signals were blocked by adding excess 
unconjugated trastuzumab (Fig. 1a, b). Conversely, DC101IR700 fluorescence signals were not detected in NCI-N87 cells (Fig. 1a, b), nor were Tra-IR700 or DC101-IR700 fluorescence signals detected in HER2-negative MKN45 and BALB/3T3 cells (Fig. 1c, d). MFI compared to isotype control ratios was $134.0 \pm 16.0$ for Tra-IR700 and $1.4 \pm 0.07$ for DC101-IR700 in NCI-N87 cells, and 2.6 \pm 0.07 and $1.0 \pm 0.05$, respectively in MKN45 cells, and $1.42 \pm 0.03$ and $1.12 \pm 0.07$, respectively in BALB/3T3 cells (means \pm SEM, $n=3$ ) (Fig. 1e). Furthermore, to demonstrate the absence of human VEGFR-2 in NCI-N87 cells, fluorescence signals of ramucirumab conjugated to IR700 (Ram-IR700)-treated NCI-N87 cells were detected by fluorescence microscopy and flow cytometry. Ram-IR700 fluorescence signals were not detected in NCI-N87 cells (Supplementary Fig. 1). Then, to prove that ramucirumab is not cross-reactive to mouse VEGFR-2 and DC101 is not cross-reactive to human VEGFR-2, fluorescence signals of Ram-IR700- or DC101IR700-treated human vascular endothelial cells HUEhT-1 or murine vascular endothelial cells TKD2 were examined by fluorescence microscopy. In HUEhT-1 cells, fluorescence signals of Ram-IR700 were confirmed in the cytosols, but fluorescence signal of DC101-IR700 was not detected. On the contrary, in TKD2 cells, fluorescence signal of DC101IR700 was confirmed, but that of Ram-IR700 was not (Supplementary Fig. 1b).

\section{Comparison of phototoxic cell death between Tra-IR700 and DC101-IR700-mediated NIR-PIT in vitro}

Previous studies showed that tumor cell death in response to NIR-PIT is rapidly induced through membrane damage, which can be detected by the LIVE/DEAD assay [15]. Cell death percentage was significantly increased upon NCIN87 cell treatment with Tra-IR700 followed by NIR light irradiation and was NIR light dose dependent. Conversely, cell death was not induced upon DC101-IR700 treatment followed by NIR light irradiation (Fig. 2a). Moreover, cell death was not induced by either Tra-IR700 or DC101-IR700 treatment followed by NIR light irradiation in HER2-negative MKN45 and BALB/3T3 cells (Fig. 2b). Trypan blue dye exclusion assay showed that long-term phototoxicity was observed upon NCI-N87 cell treatment with Tra-IR700 but not DC101-IR700, followed by NIR light irradiation (Fig. 2c).

\section{Comparison of Tra-IR700 and DC101-IR700 in vivo distribution}

To confirm target-specific Tra-IR700 and DC101-IR700 localization in vivo, serial fluorescence images were obtained 1, 2, 3, and 5 days after intravenous injection
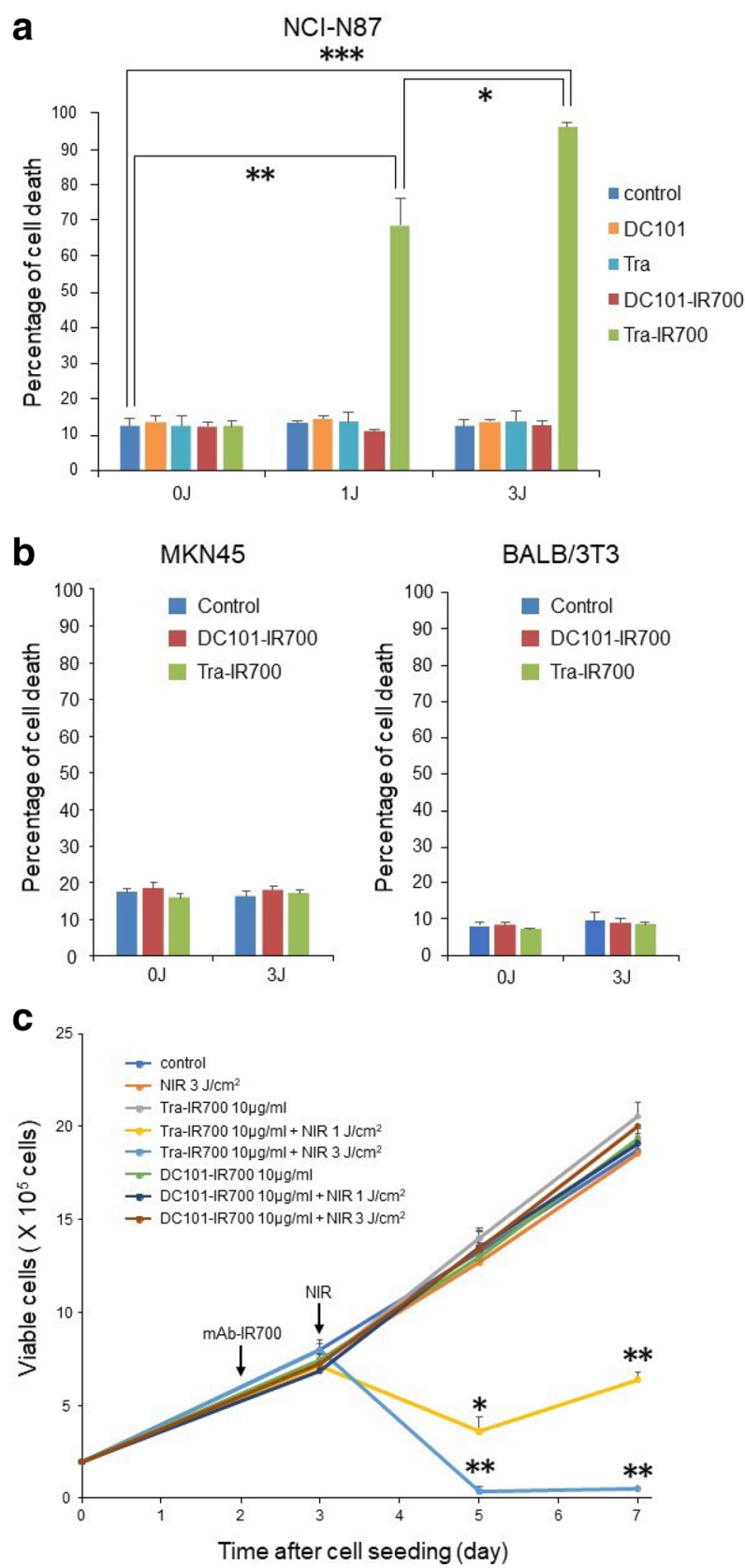

Fig. 2 Evaluation of cell damage by NIR-PIT in vitro with Tra-IR700 or DC101-IR700. a, b Induction of NIR light dose-dependent cell death in NCI-N87, MKN45, and BALB/3T3 cells by NIR-PIT with Tra-IR700 as shown by the percentage of cell death. Data are presented as the means \pm SEM $(n=3, * P<0.05, * * P<0.01$, Student's $t$ test). Comparison with control indicates lack of cytotoxicity associated with mAb-IR700 treatment or NIR irradiation in BALB/3T3 cells. c Long-term phototoxicity was observed upon NCI-N87 cell treatment with Tra-IR700 but not DC101-IR700, followed by NIR light irradiation by trypan blue dye exclusion assay. Data are presented as means \pm SEM $(n=3, * P<0.001, * * P<0.0001$ vs. control, Student's $t$ test) 
of either $100 \mu \mathrm{g}$ Tra-IR700 or DC101-IR700 in the NCIN87 xenograft tumor model. IR700 fluorescence signals were detected in NCI-N87 tumors following Tra-IR700 or DC101-IR700 injection. Serial imaging analysis showed that maximum IR700 signals were obtained 1 day after $\mathrm{mAb}$ IR700 injection (Fig. 3a, b). Next, to examine target specificity, Tra-IR700 or DC101-IR700 was injected to mice bearing NCI-N87 and HER2-negative BALB/3T3 tumors. Whereas Tra-IR700 specifically localized in NCI-N87 tumors but not in BALB/3T3 tumors, DC101-IR700 localized in both NCIN87 and BALB/3T3 tumors (Fig. 3c). Moreover, we investigated the distribution of DC101-IR700 in major organs by ex vivo fluorescence imaging because DC101 binds to VEGFR-2 on vascular endothelium not only in tumor tissue, but also in normal tissue. Ex vivo fluorescence image of dissected NCI-N87 tumor and organs was obtained at 1 day after intravenous injection of $100 \mu \mathrm{g}$ DC101-IR700. Fluorescence imaging demonstrated that among the non-tumorous organs, the liver exhibited higher accumulation of DC101IR700 than NCI-N87 tumor did, the kidneys showed similar accumulation as the tumor, and the other organs showed lower than that in the tumor (Supplementary Fig. 2).

\section{Tumor microdistribution of trastuzumab and DC101 in NCI-N87 tumors}

To investigate trastuzumab and DC101 tumor microdistribution in NCI-N87 xenografts, tumors were excised 1 day after injection of Cy5-conjugated trastuzumab (Tra-Cy5) and Alexa488-conjugated DC101 (DC101-Alexa488), then confocal images of frozen tumor sections were acquired. Tra-Cy5 was detected mainly on the tumor cell surface and in lysosomes, whereas DC101-Alexa488 was localized not in tumor cells but in the vascular compartment (Fig. 4a). Additionally, nonspecific IgG-Alexa488 was localized neither in tumor cells nor in the vascular compartment (Fig. 4b). Although the distribution of intravenously injected TraCy5 was heterogenous, staining results revealed that TraAlexa488 was homogeneously distributed in NCI-N87 tumor cells (Fig. 4c).

\section{Tra-IR700 or DC101-IR700-mediated phototherapeutic effects with NIR light in NCI-N87 tumors}

Therapeutic effect in response to Tra-IR700 or DC101-IR700-mediated NIR-PIT was examined in NCIN87 tumor-bearing mice. NCI-N87 tumors reached approximately $100 \mathrm{~mm}^{3}$ in volume 14 days after subcutaneous injection. Mice were then randomized into six groups, mAb-IR700 was intravenously injected, and tumors were irradiated with a single dose of NIR light the next day. Significant reduction of NCI-N87 tumor volume was observed for Tra-IR700 or DC101-IR700 treatments followed by NIR light irradiation, compared with the control group (day 14) $(n=10,14$ days after initial treatment; $* P<0.005$ : TraIR700 with NIR light vs. untreated control; $* * P<0.0005$ : DC101-IR700 with NIR light vs. untreated control; Student's $t$ test) (Fig. 5a). Treatment with each agent followed by NIR light irradiation also enhanced survival, compared to control group $(n=10 ; * P<0.005$ : Tra-IR700 with NIR light vs. untreated control: ${ }^{* *} P<0.001$ : DC101-IR700 with NIR light vs. untreated control; log rank test) (Fig. 5b).

To investigate the mechanism of phototoxicity in response to DC101-IR700-mediated NIR-PIT, we analyzed the MVD of treated tumors using anti-CD31 immunostaining (Fig. 5c). The mean MVD value was $26.9 \pm 3.2$ or $19.6 \pm 2.5$ in untreated controls or DC101 treatment, respectively, and $20.1 \pm 2.3$ or $12.7 \pm 1.1$ for Tra-IR700 or DC101-IR700 treatment followed by NIR light irradiation, respectively (Fig. 5d). MVD of the DC101-IR700 with NIR irradiation group was significantly lower than that of the untreated control group $(n=3 ; * P<0.05$, Student's $t$ test). Moreover, we detected destruction of the vasculature and from these vessels infiltration of erythrocytes into the surrounding tumor tissue occurred (Fig. 5c). MVDs of the DC101 group and the Tra-IR700 with NIR irradiation group were also albeit not significantly lower than that of the untreated control group. Next, in vivo tumor microdistribution after NIR-PIT was analyzed by fluorescence microscopy to confirm that NIRPIT with DC101-IR700 could achieve super enhanced permeability and retention (SUPR) effect proposed by Sano and Nagaya et al. [27, 28]. SUPR effects have been reported to enable the deeper redistribution of circulating or reinjected APCs and other nano-sized agents within treated tumor beds after NIR-PIT. The concept of SUPR effect is described in Supplementary Fig. 3. In this study, tumors were harvested after treatment of either Tra-IR700 injection, DC101-IR700 injection, Tra-IR700 injection with NIR light, or DC101IR700 injection with NIR light, followed by Tra-IR700 injection for fluorescence imaging. Tra-IR700 was distributed in deep tumors when treated with Tra-IR700 injection with NIR light followed by Tra-IR700 injection, in contrast, Tra-IR700 was distributed surface of the tumors in other treatment groups $(n=3)$ (Fig. 5e).

\section{Discussion}

NIR-PIT constitutes a highly selective cancer therapy, based on a molecularly targeted mAb conjugated to the photosensitizer IR700, which is activated by focal NIR light irradiation leading to rapid necrotic cell death by cell membrane rupture. Notably, mAb-IR700 binds to target proteins specifically without hampering tumor vessels $[15,29]$. Previous studies show that NIR-PIT efficacy is 
a

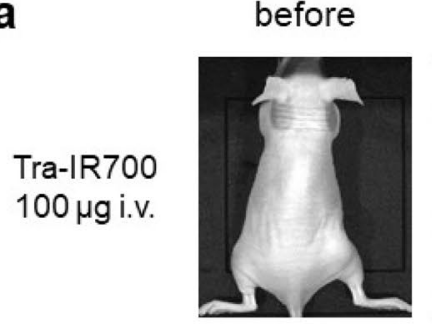

1 day
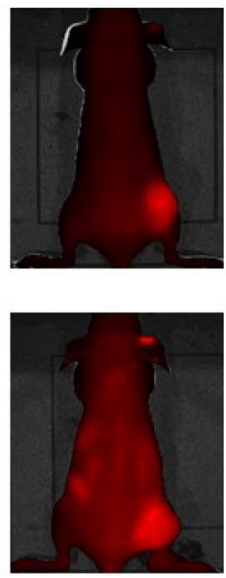

b

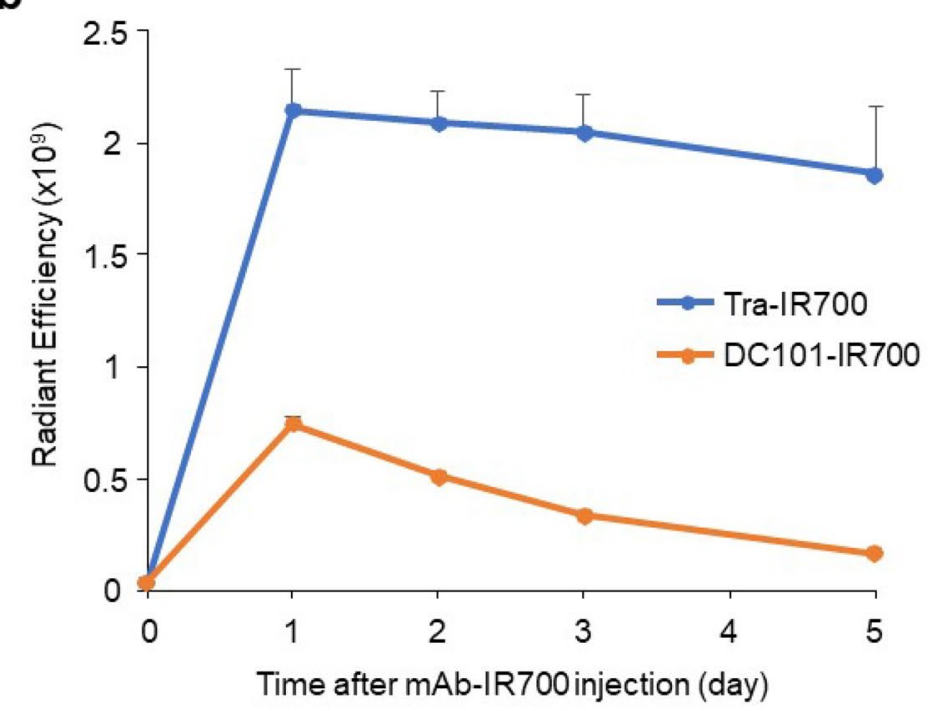

C

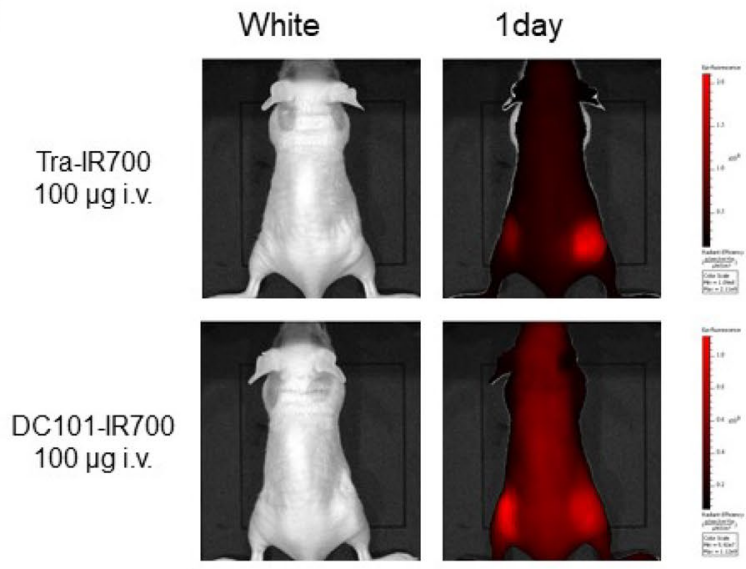

Fig. 3 In vivo biodistribution of Tra-IR700 and DC101-IR700. a NCI-N87 tumor xenografts visualized with IR700 fluorescence after intravenous injection of $100 \mu \mathrm{g}$ Tra-IR700 or DC101-IR700. b Quantitative analysis of IR700 fluorescence signal radiant efficiency detected in NCI-N87 tumors following injection of Tra-

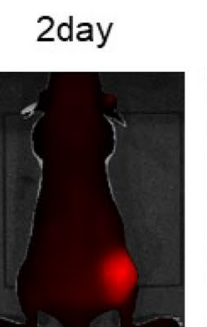

3day
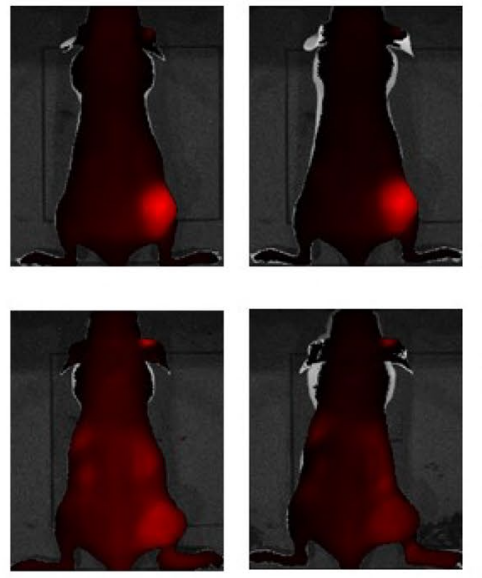

5day
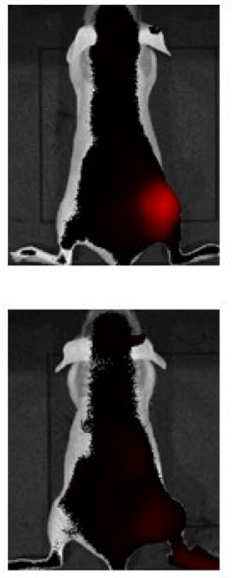

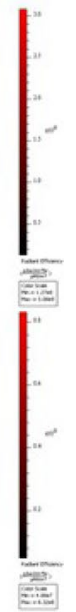

\section{.}


Fig. 4 Microdistribution of trastuzumab and DC101 in NCIN87 tumors. a Upper left, color image of DAPI staining (blue). Upper right, color image of DC101-Alexa488 fluorescence (green) in the same regions as left. Lower left, color image of Tra-Cy5 fluorescence (red) in the same regions as above. Lower right, color composite image of DAPI staining (blue), Tra-Cy5 (red) and DC101Alexa488 fluorescence (green). Scale bar $50 \mu \mathrm{m}$. b Upper left, color image of DAPI staining (blue). Upper right, color image of nonspecific IgG-Alexa488 fluorescence (green) in the same regions as left. Lower right, color composite image of DAPI staining (blue), and nonspecific IgG-Alexa488 fluorescence (green). c Upper left, color image of DAPI staining (blue). Upper right, color image of TraAlexa488 staining (green) in the same regions as left. Lower left, color image of Tra-Cy5 fluorescence (red) in the same regions as above. Lower right, color composite image of DAPI staining (blue), Tra-Cy5 (red) and Tra-Alexa488 fluorescence (green) a
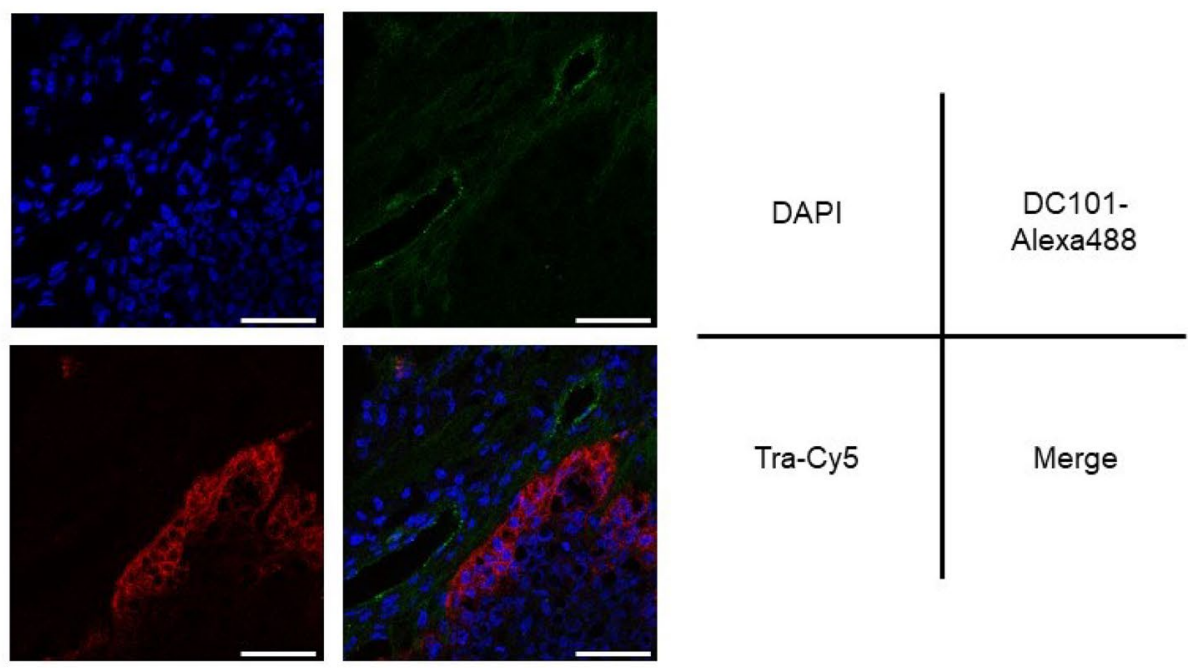

b
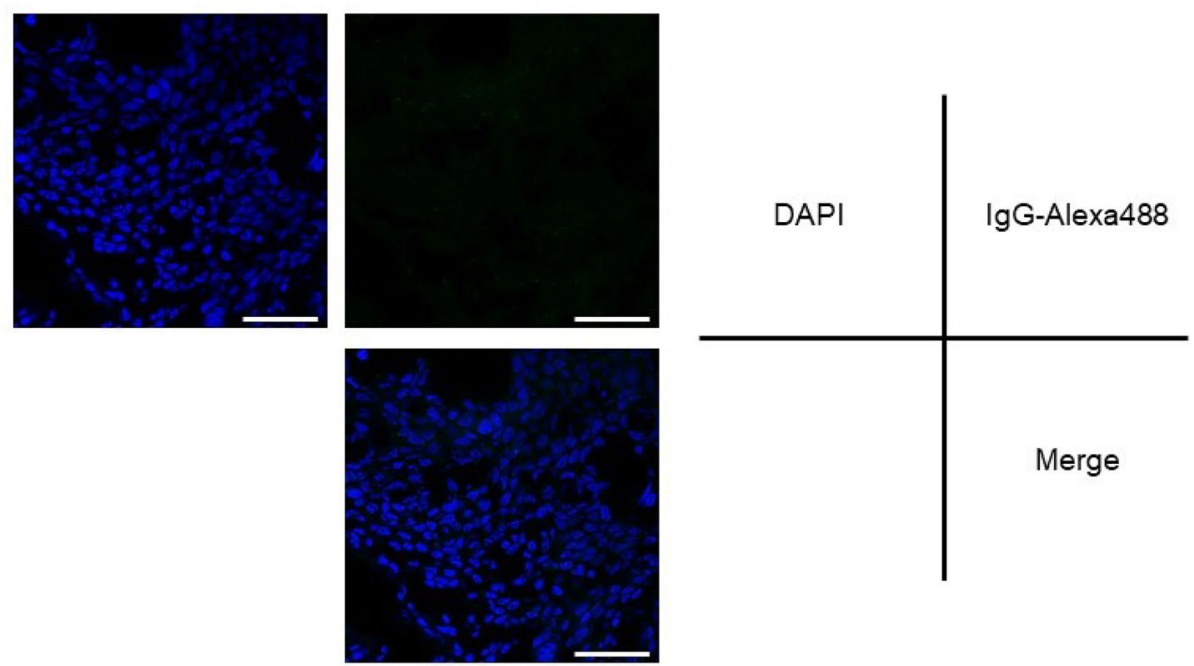

c
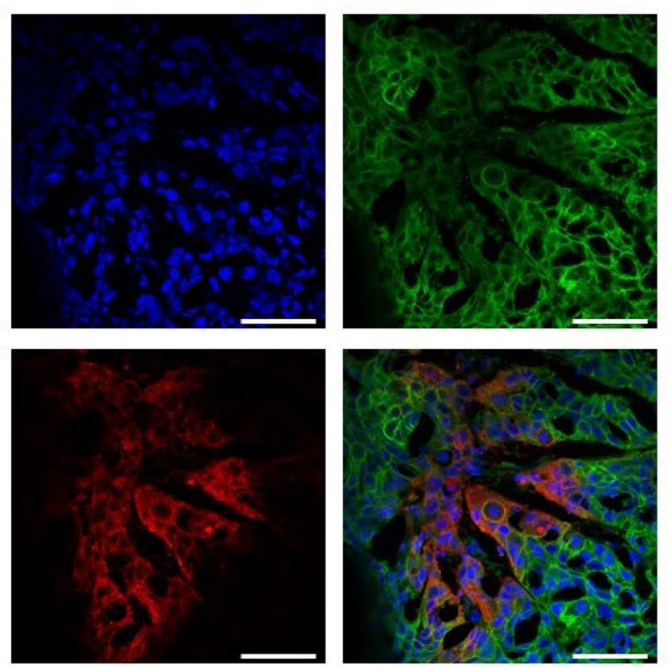

enhanced by repeating treatment, combining mAb-IR700 conjugates recognizing different molecules or epitopes, and adding chemotherapeutic agents $[16,17,22,27,28$, 30]. In the present study, we demonstrate the feasibility of
VEGFR-targeted NIR-PIT, which targets molecules differing from conventional NIR-PIT cell membrane protein targets, based on the hypothesis that disrupting tumor vessels may constitute another strategy to enhance conventional 
a

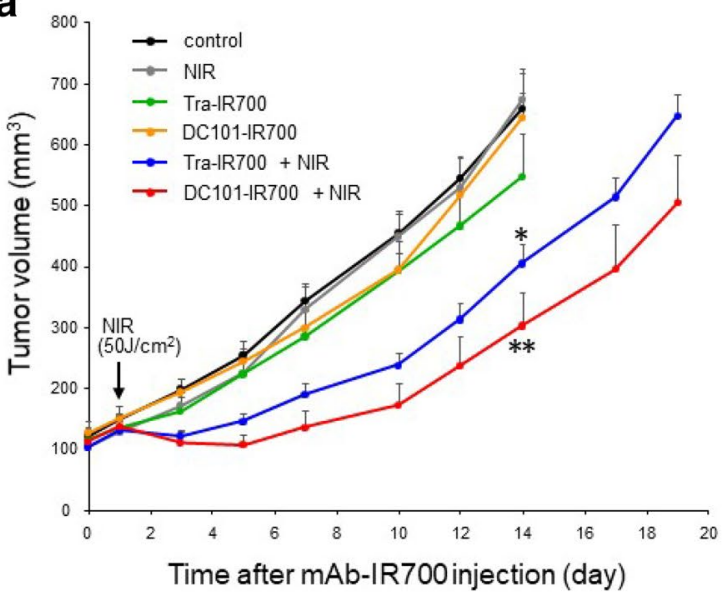

C

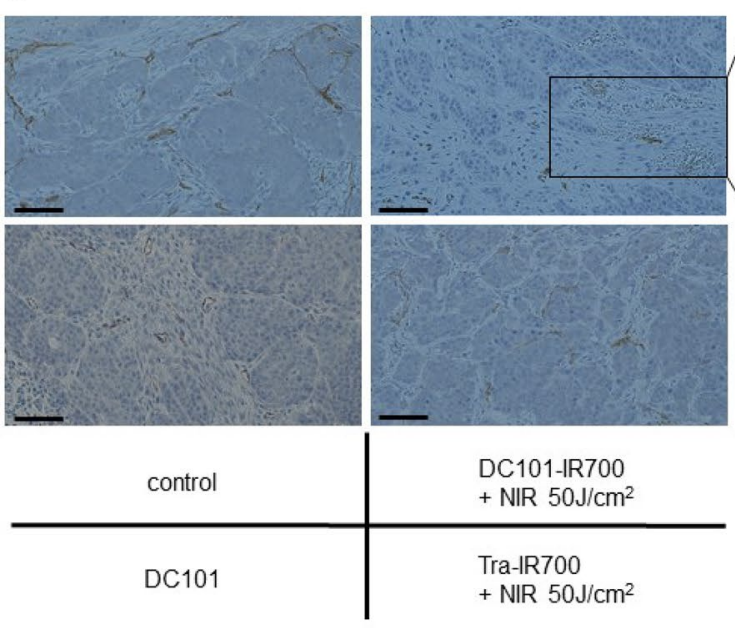

e
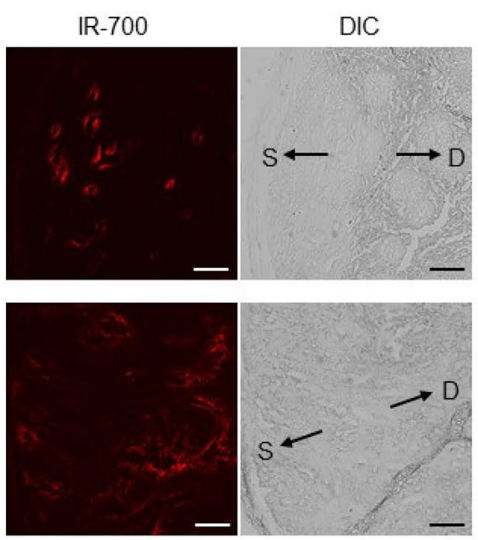

IR-700
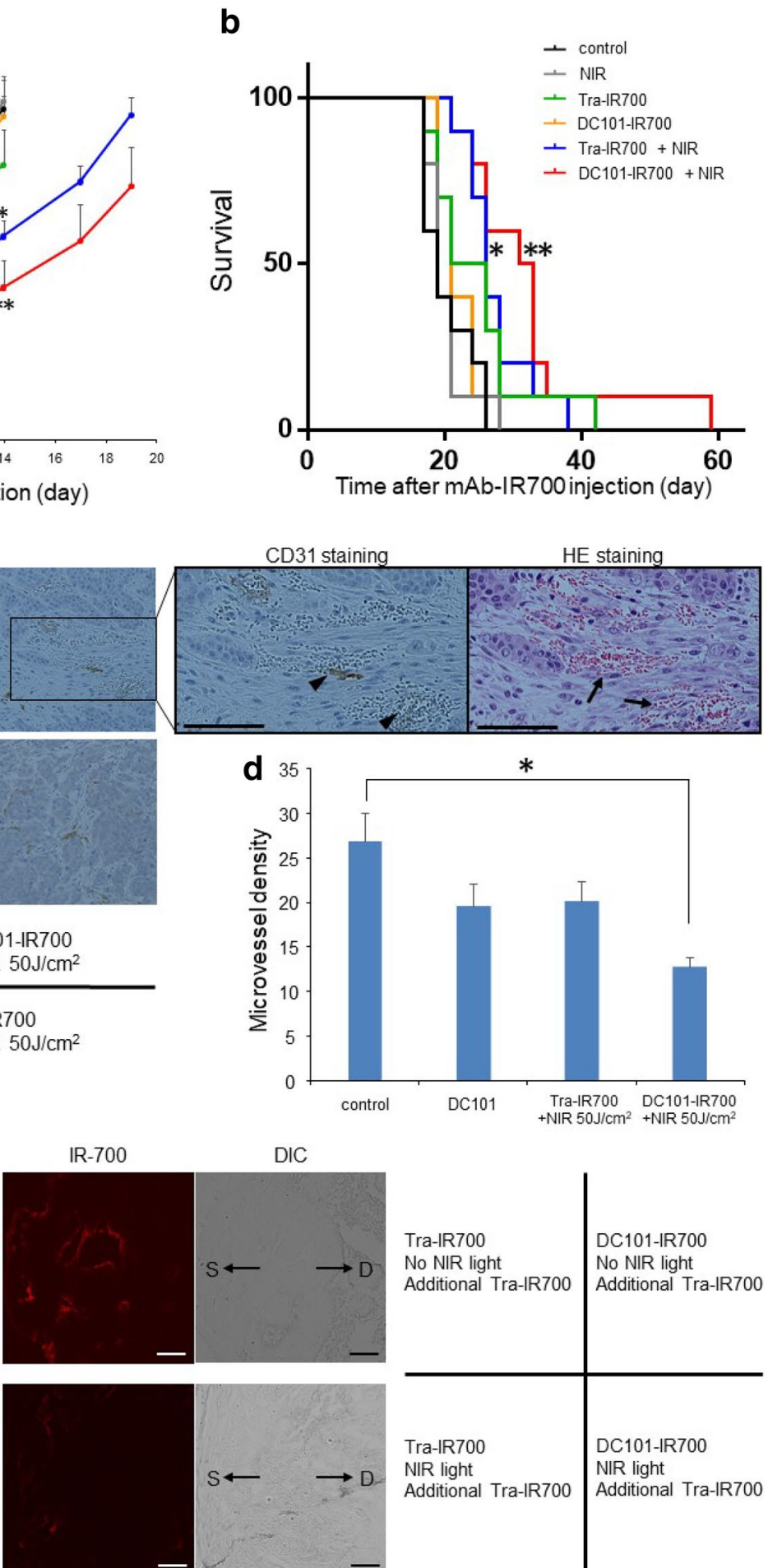

NIR-PIT efficacy via a different phototoxicity mechanism. We employed DC101, a mAb targeting VEGFR-2 expressed on intratumoral vascular endothelium, which currently has indications for treating advanced or metastatic gastric or gastroesophageal junction adenocarcinoma, metastatic colorectal cancer, and metastatic non-small cell lung cancer. Our findings confirm DC101IR700 as an efficacious novel candidate for NIR-PIT agents.

Consistent with our previous studies [16-22], HER2specific Tra-IR700 localization and Tra-IR700-mediated NIR-PIT anti-NCI-N87 tumor efficacy were obtained both in vitro and in vivo. Upon DC101-IR700 treatment 
4Fig. 5 In vivo phototherapeutic effect of Tra-IR700 and DC101IR700 with NIR irradiation on NCI-N87 tumor xenografts. a Tumor volume of NCI-N87 in the groups of Tra-IR700 with NIR light and DC101-IR700 with NIR light compared to the untreated control group. Data are presented as the means \pm SEM $(n=10$ in each group, 14 days after initial treatment; $* P<0.005$ : Tra-IR700 with NIR light vs. untreated control; $* * P<0.0005$ : DC101-IR700 with NIR light vs. untreated control; Student's $t$ test). b Relative survival upon mouse treatment with Tra-IR700 with NIR light and DC101IR700 with NIR light compared to untreated controls $(n=10$ in each group; $* P<0.005$ : Tra-IR700 with NIR light vs. untreated control: $* * P<0.001$ : DC101-IR700 with NIR light vs. untreated control; $\log$ rank test). c NCI-N87 tumor tissue section immunostained with the anti-CD31 antibody. Representative areas with highest density of microvessels in NCI-N87 tumor xenografts are shown. Arrow head: destruction of the vasculature. Arrow: extravasation of erythrocytes. Scale bar $100 \mu \mathrm{m}$. d MVD staining in the DC101-IR700 with NIR irradiation and Tra-IR700 with NIR irradiation groups compared to the DC101 treatment or untreated control group. Data are presented as the means $\pm \operatorname{SEM}(n=3$ in each group; $* P<0.05$, Student's $t$ test). e Tumor microdistribution analysis after NIR-PIT. Tumors were treated either Tra-IR700 or DC101-IR700-mediated NIR-PIT treatment followed by Tra-IR700 injection. Data are representative of three independent experiments of frozen tumor sections. S: tumor surface, D: deep tumor, Scale bar $200 \mu \mathrm{m}$, DIC differential interference contrast

of NCI-N87 cells in vitro, fluorescence signal was not detected by either flow cytometry or fluorescence microscopy, and cytotoxic effect was not induced following NIR light irradiation. Conversely, DC101-IR700 localized in NCI-N87 tumors as determined by in vivo imaging and by confocal microscopy of the harvested tumor. Additionally, antitumor effect was observed with DC101-IR700-mediated NIR-PIT in NCI-N87 tumors in vivo. The intensity of DC101-IR700 within the tumor was lower than that of Tra-IR700, reflecting that the amount of DC101-IR700 conjugated to vascular endothelium in tumor is lower than that of Tra-IR700 conjugated to cancer cell membrane and internalized into cancer cells. Previous studies revealed that there is a correlation between the magnitude of binding of mAb-IR700 to target cells and a stronger NIR-PIT effect in conventional PIT [31]. However, in this study, therapeutic effect by NIR-PIT with DC101-IR700 tended to be stronger than that by NIR-PIT with Tra-IR700 even though fluorescence intensity of DC101-IR700 was lower than that of Tra-IR700, and it seems to be difficult to predict the therapeutic effect from fluorescence intensity in NIR-PIT with DC101-IR700. To elucidate the mechanism of NIR-PIT with DC101-IR700, we confirmed the different localization of DC101 and trastuzumab by confocal microscopy of the harvested tumors from Tra-Cy5 and DC101-Alexa488-injected mice. Tra-Cy5 fluorescence was detected on the NCI-N87 tumor cell surface and lysosomes, whereas DC101-Alexa488 was detected in the lumen of blood vessels. Following DC101-IR700-mediated NIR-PIT, tumor MVD, which is commonly assessed as an indicator of angiogenesis, was significantly reduced compared with untreated controls. Conversely, MVDs of Tra-IR700-mediated NIR-PIT-treated tumors and DC101treated tumors (without NIR light) tended to decrease compared with untreated controls but these differences were not significant. Furthermore, destruction of the vasculature and erythrocyte infiltration from these vessels was observed in the tumor tissue treated by NIR-PIT with DC101-IR700. These findings suggest that NIR-PIT with DC101-IR700 confers antitumor effects with a different mechanism, involving tumor angiogenesis, from that of conventional NIR-PIT, which targets particular tumor cell membrane antigens.

Our previous studies showed that NIR-PIT induced increasing permeability of nanoparticles and macromolecules in the treated tumor compared to untreated tumor, termed SUPR effect [27, 28]. Conventional NIR-PIT (TraIR700 injection with NIR light followed by Tra-IR700 injection) consistently lead to increased IR700 signals in the deep tumor, while DC101-IR700-mediated NIR-PIT was not able to achieve it. This result suggests that damaging tumor microvasculature in response to DC101-IR700-mediated NIR-PIT might hamper deep-tumor microdistribution of the macromolecules. Moreover, conventional NIR-PIT induces immunogenic cell death (ICD) capable of inducing dendritic cell maturation that drive the differentiation of naïve T cells into effectors $[32,33]$. On the other hand, it is not unclear that NIR-PIT with DC101-IR700 has the ability to induce ICD, and it might also prevent the infiltration of lymphocytes involved in the immune response that can induce ICD as well as macromolecules. Therefore, further studies are planned to analyze the immunological mechanism of VEGFR-2-targeted NIR-PIT.

Conventional NIR-PIT can be applied for tumors that express target molecules on the cell surface; therefore, various mAb-IR700 conjugates may be needed depending on antigen expression. In addition, intratumoral heterogeneity of the target molecule as well as heterogeneous tumor microdistribution of mAb-IR700 conjugates could limit therapeutic efficacy of conventional NIR-PIT. Even though it was confirmed that HER2 was homogenously expressed in NCI-N87 tumor xenograft by immunohistochemistry, the distribution of intravenously administered trastuzumab conjugated to fluorophore was heterogeneous, indicating the limited accessibility of mAb-IR700 conjugates to the targeted tumor antigens. Conversely, cancer neovasculaturetargeted NIR-PIT can be applied to the majority of solid cancer types, including gastric cancer, and can be used as an alternative treatment to NIR-PIT targeting particular tumor cell membrane antigens for the above reasons, and, therefore, holds a promise for future clinical translation using anti-human VEGFR-2 antibody ramucirumab-IR700 conjugate [34]. Anti-VEGFR-2 antibody binds to the vascular 
endothelium of not only the tumor tissue, but also the normal tissue, whereas NIR-PIT only damages the area irradiated with NIR light; therefore, the normal tissue toxicity could be limited.

\section{Conclusions}

We demonstrated a new type of NIR-PIT that targets VEGFR-2 expressed on vascular endothelium in tumors, leading to antitumor effect induction, and its mechanism was considered to be different compared with conventional NIR-PIT targeting tumor cell membranes. Although VEGFR-2-targeted NIR-PIT effects were not observed in vitro because of the absence of VEGFR-2 expression, it was confirmed in in vivo via selective vascular localization of DC101 and significant decrease of tumor MVD following NIR-PIT. As demonstrated by REGARD trial [13], ramucirumab is effective against gastric cancer even with a single agent, and we are convinced that the application of ramucirumab for NIR-PIT will further enhance the antitumor effect on gastric cancer. Furthermore, VEGFR-2 is upregulated in many solid cancers, NIR-PIT targeting VEGFR-2 may be applicable to various cancer types in a clinical setting.

Acknowledgements We would like to thank Mr. Kazuya Sakurai and Ms. Mamiko Ohwada for their pathological assistants with the experiments. This study was supported partly by a Grant-in-Aid for Young Scientists (A) (JSPS KAKENHI 26710010), Grant-in-Aid for Scientific Research (B) (JSPS KAKENHI 18H03523), funding from a research Grant of Bristol-Myers Squibb (M.M.), and funding from the Intramural Research Program of the National Institutes of Health, National Cancer Institute, Center for Cancer Research (1ZIABC011513).

Author contributions Conceptualization: MM; data duration: TN, KI and MM; formal analysis: TN, KI and MM; funding acquisition: MM and $\mathrm{HK}$; supervision: HK and MS; writing: TN, MM and HK.

\section{Compliance with ethical standards}

Conflict of interest The authors declare that they have no conflict of interest.

\section{References}

1. Wagner AD, Grothe W, Haerting J, Kleber G, Grothey A, Fleig WE. Chemotherapy in advanced gastric cancer: a systematic review and meta-analysis based on aggregate data. J Clin Oncol. 2006;24:2903-9.

2. Gravalos C, Jimeno A. HER2 in gastric cancer: a new prognostic factor and a novel therapeutic target. Ann Oncol. 2008;19:1523-9.

3. Hofmann M, Stoss O, Shi D, Büttner R, van de Vijver M, Kim W, et al. Assessment of a HER2 scoring system for gastric cancer: results from a validation study. Histopathology. 2008;52:797-805.
4. Tanner M, Hollmén M, Junttila TT, Kapanen AI, Tommola S, Soini Y, et al. Amplification of HER-2 in gastric carcinoma: association with Topoisomerase IIalpha gene amplification, intestinal type, poor prognosis and sensitivity to trastuzumab. Ann Oncol. 2005;16:273-8.

5. Bang YJ, Van Cutsem E, Feyereislova A, Chung HC, Shen L, Sawaki A, et al. Trastuzumab in combination with chemotherapy versus chemotherapy alone for treatment of HER2-positive advanced gastric or gastro-oesophageal junction cancer (ToGA): a phase 3, open-label, randomised controlled trial. Lancet. 2010;376:687-97.

6. Krupitskaya Y, Wakelee HA. Ramucirumab, a fully human $\mathrm{mAb}$ to the transmembrane signaling tyrosine kinase VEGFR-2 for the potential treatment of cancer. Curr Opin Investig Drugs. 2009;10:597-605.

7. Aguayo A, Kantarjian H, Manshouri T, Gidel C, Estey E, Thomas $\mathrm{D}$, et al. Angiogenesis in acute and chronic leukemias and myelodysplastic syndromes. Blood. 2000;96:2240-5.

8. Carmeliet P, Jain RK. Angiogenesis in cancer and other diseases. Nature. 2000;407:249-57.

9. Ferrara N. Molecular and biological properties of vascular endothelial growth factor. J Mol Med (Berl). 1999;77:527-43.

10. Klagsbrun M, D'Amore PA. Vascular endothelial growth factor and its receptors. Cytokine Growth Factor Rev. 1996;7:259-70.

11. Neufeld G, Cohen T, Gengrinovitch S, Poltorak Z. Vascular endothelial growth factor (VEGF) and its receptors. FASEB J. 1999;13:9-22.

12. Jung YD, Mansfield PF, Akagi M, Takeda A, Liu W, Bucana CD, et al. Effects of combination anti-vascular endothelial growth factor receptor and anti-epidermal growth factor receptor therapies on the growth of gastric cancer in a nude mouse model. Eur J Cancer. 2002;38:1133-40.

13. Fuchs CS, Tomasek J, Yong CJ, Dumitru F, Passalacqua R, Goswami C, et al. Ramucirumab monotherapy for previously treated advanced gastric or gastro-oesophageal junction adenocarcinoma (REGARD): an international, randomised, multicentre, placebocontrolled, phase 3 trial. Lancet. 2014;383:31-9.

14. Wilke H, Muro K, Van Cutsem E, Oh SC, Bodoky G, Shimada Y, et al. Ramucirumab plus paclitaxel versus placebo plus paclitaxel in patients with previously treated advanced gastric or gastrooesophageal junction adenocarcinoma (RAINBOW): a doubleblind, randomised phase 3 trial. Lancet Oncol. 2014;15:1224-355.

15. Mitsunaga M, Ogawa M, Kosaka N, Rosenblum LT, Choyke PL, Kobayashi H. Cancer cell-selective in vivo near infrared photoimmunotherapy targeting specific membrane molecules. Nat Med. 2011;17:1685-91.

16. Ito K, Mitsunaga M, Arihiro S, Saruta M, Matsuoka M, Kobayashi $\mathrm{H}$, et al. Molecular targeted photoimmunotherapy for HER2-positive human gastric cancer in combination with chemotherapy results in improved treatment outcomes through different cytotoxic mechanisms. BMC Cancer. 2016;16:37.

17. Ito K, Mitsunaga M, Nishimura T, Kobayashi H, Tajiri H. Combination photoimmunotherapy with monoclonal antibodies recognizing different epitopes of human epidermal growth factor receptor 2: an assessment of phototherapeutic effect based on fluorescence molecular imaging. Oncotarget. 2016;7:14143-522.

18. Sato K, Choyke PL, Kobayashi H. Photoimmunotherapy of gastric cancer peritoneal carcinomatosis in a mouse model. PLoS One. 2014;9:e113276.

19. Sato K, Hanaoka H, Watanabe R, Nakajima T, Choyke PL, Kobayashi $\mathrm{H}$. Near infrared photoimmunotherapy in the treatment of disseminated peritoneal ovarian cancer. Mol Cancer Ther. 2015; 14:141-50.

20. Sato K, Nagaya T, Choyke PL, Kobayashi H. Near infrared photoimmunotherapy in the treatment of pleural disseminated NSCLC: preclinical experience. Theranostics. 2015;5:698-709. 
21. Shimoyama K, Kagawa S, Ishida M, Watanabe S, Noma K, Takehara K, et al. Viral transduction of the HER2-extracellular domain expands trastuzumab-based photoimmunotherapy for HER2-negative breast cancer cells. Breast Cancer Res Treat. 2015;149:597-605.

22. Ito K, Mitsunaga M, Nishimura T, Saruta M, Iwamoto T, Kobayashi $\mathrm{H}$, et al. Near-infrared photochemoimmunotherapy by photoactivatable bifunctional antibody-drug conjugates targeting human epidermal growth factor receptor 2 positive cancer. Bioconjug Chem. 2017;28:1458-69.

23. Ishida M, Sekine S, Taniguchi H, Fukagawa T, Katai H, Kushima R. Consistent absence of HER2 expression, regardless of HER2 amplification status, in neuroendocrine carcinomas of the stomach. Histopathology. 2014;64:1027-31.

24. Rüschoff J, Hanna W, Bilous M, Hofmann M, Osamura RY, Penault-Llorca F, et al. HER2 testing in gastric cancer: a practical approach. Mod Pathol. 2012;25:637-50.

25. Tomayko MM, Reynolds CP. Determination of subcutaneous tumor size in athymic (nude) mice. Cancer Chemother Pharmacol. 1989;24:148-54.

26. Maeda K, Chung YS, Takatsuka S, Ogawa Y, Sawada T, Yamashita $\mathrm{Y}$, et al. Tumor angiogenesis as a predictor of recurrence in gastric carcinoma. J Clin Oncol. 1995;13:477-81.

27. Sano K, Nakajima T, Choyke PL, Kobayashi H. Markedly enhanced permeability and retention effects induced by photoimmunotherapy of tumors. ACS Nano. 2013;7:717-24.

28. Nagaya T, Nakamura Y, Sato K, Harada T, Choyke PL, Kobayashi H. Improved micro-distribution of antibody-photon absorber conjugates after initial near infrared photoimmunotherapy (NIR-PIT). J Control Release. 2016;232:1-8.
29. Liang CP, Nakajima T, Watanabe R, Sato K, Choyke PL, Chen $\mathrm{Y}$, et al. Real-time monitoring of hemodynamic changes in tumor vessels during photoimmunotherapy using optical coherence tomography. J Biomed Opt. 2014;19:98004.

30. Mitsunaga M, Nakajima T, Sano K, Choyke PL, Kobayashi H. Near-infrared theranostic photoimmunotherapy (PIT): repeated exposure of light enhances the effect of immunoconjugate. Bioconjug Chem. 2012;23:604-9.

31. Nakajima T, Sato K, Hanaoka H, Watanabe R, Harada T, Choyke $\mathrm{PL}$, et al. The effects of conjugate and light dose on photo-immunotherapy induced cytotoxicity. BMC Cancer. 2014;14:389.

32. Ogawa M, Tomita Y, Nakamura Y, Lee MJ, Lee S, Tomita S, et al. Immunogenic cancer cell death selectively induced by near infrared photoimmunotherapy initiates host tumor immunity. Oncotarget. 2017;8:10425-36.

33. Nagaya T, Friedman J, Maruoka Y, Ogata F, Okuyama S, Clavijo PE, et al. Host immunity following near-infrared photoimmunotherapy is enhanced with PD-1 checkpoint blockade to eradicate established antigenic tumors. Cancer Immunol Res. 2019;7:401-13.

34. Smith NR, Baker D, James NH, Ratcliffe K, Jenkins M, Ashton $\mathrm{SE}$, et al. Vascular endothelial growth factor receptors VEGFR-2 and VEGFR-3 are localized primarily to the vasculature in human primary solid cancers. Clin Cancer Res. 2010;16:3548-61.

Publisher's Note Springer Nature remains neutral with regard to jurisdictional claims in published maps and institutional affiliations. 